\title{
Research of the surface properties of the thermoplastic copolymer of Vinilidene Fluoride and Tetrafluoroethylene modified with radio- frequency magnetron sputtering for medical application
}

\author{
S.I. Tverdokhlebov ${ }^{a}$, E.N. Bolbasov ${ }^{a}$, E.V. Shesterikov ${ }^{a}$, A.I. Malchikhina ${ }^{a}$, V.A. Novikov ${ }^{b}$, \\ Y.G. Anissimov
}

a) Tomsk Polytechnic University, 634050, 30, Lenin Avenue, Tomsk, Russia.

b) Tomsk State University, 634050, 36, Lenin Avenue, Tomsk, Russia.

c) School of Biomolecular and Physical Sciences, Griffith University, Southport, Queensland 4222, Australia.

Corresponding author: Sergei I. Tverdokhlebov, e-mail: tverd@tpu.ru, phone: +7(3822)5634-37, address: 40A-2, Istochnaya st., Tomsk, Russia, 634050.

E.N. Bolbasov, e-mail: ebolbasov@ gmail.com, phone: +7(3822)56-34-37, address: 45A-49, Melnichnaya st., Tomsk, Russia, 634050.

E.V. Shesterikov, e-mail: shesterikov_e@mail.ru, phone: +7(3822)56-34-37, address: 2-117, Botanicheskiy st., Tomsk, Russia, 634050.

A.I. Malchikhina, e-mail: alyonamalchikhina@gmail.com, phone: +7(3822)56-34-37, address: 20-11, Kolhoznaya st., Tomsk, Russia, 634050.

V.A. Novikov, e-mail: novikovvadim@mail.ru, address: 24-31, Ziolkovskiy st., Tomsk, Russia, 634050.

Y.G. Anissimov, e-mail: Y.Anissimov@Griffith.edu.au; address: School of Biomolecular and Physical Sciences, Gold Coast campus, Griffith University, QLD 4222, Australia.

\begin{abstract}
The properties of thin calcium-phosphate coatings formed by radio-frequency magnetron sputtering of a solid target made from hydroxyapatite on the surface of the thermoplastic copolymer of Vinilidene Fluoride and Tetrafluoroethylene (VDF-TeFE) were investigated. Atomic force microscopy energy dispersive analysis and optical goniometry showed that deposited calcium-phosphate coatings change significantly the morphological, electrical, chemical, and contact properties of the surface of the initial polymeric substrates. These modified surfaces widen the scope of medical application of the thermoplastic copolymer.
\end{abstract}

Keywords: magnetron sputtering, copolymer of Vinilidene Fluoride and Tetrafluoroethylene, 
thin calcium-phosphate coatings, wettability, surface roughness, surface potential.

\section{Highlights:}

- A method for surface modification of the thermoplastic copolymer of Vinilidene Fluoride and Tetrafluoroethylene using radio-frequency magnetron sputtering of hydroxyapatite target is proposed.

- It is demonstrated that the thermoplastic copolymer of Vinilidene Fluoride and Tetrafluoroethylene surface becomes hydrophilic as the result of the modification.

- It is shown, using atomic force microscopy that the surface potential biases into positive value field and the surface roughness parameters increase as the result of the modification.

- In-vitro testing has not found bio-toxicity of investigated surfaces.

\section{Introduction}

Fluorinated polymer materials are ubiquitous in modern medicine and are used in implants [1], membranes [2], coating of intravascular stents [3], the composite coatings [4], and the scaffolds for regenerative medicine $[5,6]$. A central role in the interaction of fluorinated polymer material with living tissues is played by its surface properties. Critical characteristics of the surface of medical products are the roughness parameters, wettability of the surface by various liquids and electrical properties [7-9]. Therefore many research groups take part in the surface modification of fluorocarbon plastics to improve its biocompatibility $[10,11]$. The focus of our study is copolymer of Vinilidene Fluoride and Tetrafluoroethylene (VDF-TeFE) and its surface modification. The structural chemical formula of the VDF-TeFE is shown in Fig 1.

$$
\left[\left(-\mathrm{CF}_{2} \mathrm{CF}_{2}-\right)_{\mathrm{m}}\left(-\mathrm{CF}_{2} \mathrm{CH}_{2}\right)_{\mathrm{p}}\right]_{\mathrm{n}}
$$

Figure 1. The structural chemical formula of the copolymer of Vinilidene Fluoride and Tetrafluoroethylene (VDF-TeFE).

The future of application of this polymer in medicine is based on a range of properties such as high chemical resistance, good mechanical properties and biological inertness [12]. It is also important that the polymer is dissolvable in the low toxic organic solvents such as acetone, 
methyl ethyl ketone, butyl acetate and ethyl acetate [13]. Modification of the polymer surface was carried out by deposition of thin $\mathrm{CaP}$ coatings with radio-frequency magnetron sputtering. The method of high frequency magnetron sputtering (RFMS) is based on the sputtering of material in vacuum due to the bombardment of the target surface with the working gas ions (usually argon) which are formed in the abnormal glow discharge plasma when a magnetic field is applied [14]. It is known that the CaP coatings formed by RFMS on metal substrates stimulate the attachment and proliferation of osteogenic cells on the surface thus providing high biocompatibility [15].

\section{Materials and methods}

The VDF-TeFE copolymer was deposited on plates of pre-polished 321 stainless steel with dimensions of $20 \times 20 \mathrm{~mm}$. Thin polymer coating was formed on one side of the plate from $2 \%$ solution of a copolymer VDF-TeFE in a mixture of organic solvents with composition $20 \%$ acetone, $20 \%$ ethyl acetate, $40 \%$ cyclohexanone and $20 \%$ butyl acetate (by mass). Preparation of VDF-TeFE copolymer solution was carried out in a hermetic reactor at $50^{\circ} \mathrm{C}$ temperature with constant stirring to obtain a homogeneous transparent solution. The solution was then cooled to room temperature and deposited on the metal plate by pneumatic spraying method. The samples were then placed in a chamber furnace, where final molding of the polymer coating was conducted under the following conditions: heating to temperature of $35^{\circ} \mathrm{C}$ at a rate of 1 degree per minute, followed by exposure at $35^{\circ} \mathrm{C}$ during $4 \mathrm{~h}$, heating to temperature of $70^{\circ} \mathrm{C}$, followed by exposure at $70^{\circ} \mathrm{C}$ during $4 \mathrm{~h}$, heating to temperature of $200^{\circ} \mathrm{C}$ at a rate of 1 degree per minute, followed by exposure at $200^{\circ} \mathrm{C}$ during 2 hours. After the completion of the thermoforming of the polymer coating the samples were removed from the oven and cooled to room temperature under room conditions. The coatings thickness, determined with the Talysurf 5 (Tyler-Hobson, England) profilometer with the method of "step", was $1.9 \pm 0.2 \mu \mathrm{m}$.

The polymer surface was modified with RFMS of hydroxyapatite solid target produced by the technology described in [15]. The "Cathode 1M" device, that allows forming thin $\mathrm{CaP}$ coatings on different materials (metals, ceramics, and polymers), was used to modify the surface. High-frequency magnetron source supplied by high frequency (HF) generator with a maximum power of $4 \mathrm{~kW}$ and operating frequency of $13.56 \mathrm{MHz}$ was placed in the vacuum chamber of the device. We used the following technological conditions: vacuum in the chamber was $5 \times 10^{-5} \mathrm{~Pa}$, working pressure of $\mathrm{Ar}-3 \times 10^{-1} \mathrm{~Pa}$ and specific radio frequency (RF) power of about $20 \mathrm{~W} / \mathrm{cm}^{2}$. Several groups of samples were prepared to study the properties of the modified VDF-TeFE 
polymer surface. The surface samples of the control group I had polymeric coating with no surface modification. The samples of the group II had surface modification duration of 10 minutes, the group III - 20 minutes, the group IV - 40 minutes, and the group V - 60 minutes.

\section{Research methods}

The study of the chemical composition of the modified polymer surface was carried out by energy dispersive spectroscopy analysis (EDS) method on the scanning electron microscope (ESEM Quanta 400 FEG from FEI) with integrated EDS-analyzer (EDS analysis system Genesis 4000, S-UTW-Si (Li) detector). Determination of the chemical composition was carried in a low vacuum mode with the pressure in the microscope chamber of $60 \mathrm{~Pa}$. In order to increase the resolution of the microscope, the accelerating voltage of $15 \mathrm{kV}$ was used (twice as high as the excitation energy of the $\mathrm{K}-\alpha$ lines of $\mathrm{Ca}$, the heaviest analyzed element). The distance between the electron source and the samples was $10 \mathrm{~mm}$; the angle between the detector and the samples was $35^{\circ}$. The method of three corrections: in the average atomic number, absorption and fluorescence was used for semi quantitative calculation of the chemical composition of the coating.

Sample's surface research was carried out using scanning electron microscopy (ESEM Quanta 400 FEG) in a low vacuum without deposition of conductive coatings in order to avoid distortion of the morphology of the investigated coatings. Investigation of the surface topography, phase contrast, and the potential distribution on the surface was carried out on the atomic force microscope (AFM) «Solver-HV» (NT-MDT) using the Kelvin method [16-17]. The measurements were conducted in air at room conditions in tapping mode using two-pass technique. The NSG11 cantilevers with needle tip curvature radius of $10 \mathrm{~nm}$ and dopant concentration of $5 \times 10^{20} \mathrm{~cm}^{-3}$ were used for experiments. The AFM images were processed using the Gwiddion 2.25 software package. The surface relief, phase contrast and the surface potential were built for all investigated groups of samples. The scanning area was set at $5 \times 5 \mu \mathrm{m}, 1 \times 1 \mu \mathrm{m}$, $10 \times 10 \mu \mathrm{m}$ surface roughness parameters were determined as the mean arithmetic deviation of the surface profile $R a$; the profile irregularity height over ten points $R z$; the maximum height $P t$ of the profile roughness; the average maximum depth of roughness valleys $R v m$; the average maximum height of roughness peaks Rpm; the mean value of the surface potential $U_{\mathrm{m}}$; the maximum value of the surface potential $U_{\max }$; and the minimum value of the surface potential $U_{\text {min }}$. Wettability of the modified polymer coatings was studied with the «Easy Drop» device (Krüss) with method of "sit" drop by measuring the contact angle of a liquid drop with volume of 
$3 \mu \mathrm{l}$ placed onto the investigated surface. Measurements of the wetting boundary angle (the contact angle) were carried out one minute after placing the liquid on the surface. In order to avoid contamination of the surface and distortion of measurement results, measurements of the contact angle were carried out immediately after surface modification. Glycerin and water were used as the wetting liquids. The total surface energy, it's polar and dispersion components were calculated with the Owens-Wendt-Rabel-Kaelble (OWRK) method [18-19].

Preliminary sample's surface toxicity research was carried out using toxicity analyser (AT05, ZAO "MBK-INVEST"). Toxicity was assessed by comparing mobility of the suspension culture of motile cells in the control solution to that in the test solution. Solution of glucose $(4 \mathrm{~g})$ and Trisodium citrate (1g) in distilled water $(100 \mathrm{~g})$ was used as the control solution. Test solutions were prepared by incubating the surface samples each in $20 \mathrm{ml}$ of the control solution in thermostat for $24 \mathrm{~h}$ at $37 \pm 2^{\circ} \mathrm{C}$. Samples for the incubations were prepared from plates of prepolished 321 stainless steel with dimensions $10 \times 10 \times 0.5 \mathrm{~mm}$. Both surfaces of the sample were coated as describe for the samples of Group I, and then one of the surfaces was modified as described for the samples of Groups II-V. The suspension culture of motile cells was prepared by placing granules of liquid nitrogen cooled bovine semen each into a test tube with $0.4 \mathrm{ml}$ of control solution preheated to $(40 \pm 2)^{\circ} \mathrm{C}$. After thawing, the content of all test tubes was thoroughly mixed together and yielded a stock solution of the suspension culture of motile cells. For testing toxicity $0.1 \mathrm{ml}$ of the stock solution was placed with ?? $20 \mathrm{ml}$ of the control and test solutions, which was then transferred onto $25 \mu \mathrm{l}$ rectangular cells of $200 \mu \mathrm{m}$ thickness. The mobility of the sperm suspension was then measured at regular time intervals until mobility in all samples was close to zero. Weighted average of the mobility ( $t_{a v}$, in arbitrary units) for each sample was calculated using equation (1):

$$
t_{a v}=\ln m_{1} \frac{\sum_{i}\left(m_{i} i\right)}{\sum_{i} m_{i}},
$$

where $m_{i}$ is the mobility value at the $i$-th time interval. Toxicity index was then calculated using equation (2):

$$
I_{t}=\frac{t_{a v}^{t}}{t_{a v}^{c}} \times 100 \%
$$

Where $t_{a v}^{t}, t_{a v}^{c}$ are weighted average of the mobility for the test and control samples. The surface sample was considered non toxic if its toxicity index was in the range of 70-120\% [20]. 


\section{Results and discussion}

Table 1 presents the results of investigation of the chemical composition of the polymer surface carried out by EDS. These results show that the basic elements of sputtering target, namely $\mathrm{Ca}, \mathrm{P}$ and $\mathrm{O}$, are determined for all groups of samples with modified surface regardless of the modification duration.

Table 1. Chemical composition of CaP coatings assessed using EDS analysis.

\begin{tabular}{|c|c|c|c|c|c|c|c|c|c|c|}
\hline \multirow{2}{*}{ Group number } & \multicolumn{8}{|c|}{ Element's content in the CaP coating, \% } & \multicolumn{2}{c|}{$\mathrm{Ca} / \mathrm{P}$} \\
\cline { 2 - 12 } & $\mathrm{C}$ & $\mathrm{O}$ & $\mathrm{F}$ & $\mathrm{Si}$ & $\mathrm{P}$ & $\mathrm{Ca}$ & $\mathrm{Fe}$ & $\mathrm{Ni}$ & $\mathrm{Cr}$ & \\
\hline I & 52.67 & 1.85 & 8.65 & 0.31 & 0 & 0 & 26.3 & 3.07 & 7.15 & - \\
\hline II & 42.01 & 1.84 & 8.41 & 0.51 & 0.42 & 0.28 & 33.27 & 4.16 & 9.09 & 0.66 \\
\hline III & 11.05 & 2.75 & 6.43 & 0.60 & 0.99 & 0.82 & 55.43 & 7.17 & 14.76 & 0.83 \\
\hline IV & 9.12 & 9.25 & 2.53 & 0.42 & 7.88 & 9.29 & 43.94 & 5.32 & 12.24 & 1.18 \\
\hline V & 8.73 & 12.27 & 1.5 & 0.41 & 11.29 & 14.21 & 36.67 & 4.58 & 10.4 & 1.25 \\
\hline
\end{tabular}

The total content of calcium, phosphorus and oxygen on the surface becomes greater with increase in the duration of the modification process (see Fig. 2), indicating the growth of grains of calcium phosphates, their merging and enlargement which leads to formation of the calcium phosphate film (see Fig. 3). In Fig. 2 peaks of Fe, Cr, Ni and Si are due to the steel substrate.

These results demonstrate the increase in the ratio $\mathrm{Ca} / \mathrm{P}$ with increasing deposition time. This relationship is probably due to the following factors: an increase in the intensity of the decomposition of phosphorus compounds as the result of RF discharge plasma and increase in the substrate temperature during deposition, causing escape of phosphorus into the pumping system, which was also noted in [21]; the phosphorus being knocked out from growing film due to bombardment by the high-energy particles [22]; Ar pressure fluctuations during the deposition process [23]. The presence of oxygen in the coatings of the group I, detectable by EDS, may be due to the presence of a polymer film formed by the residual impurities of high-boiling organic solvent (butyl acetate, and cyclohexanone). 


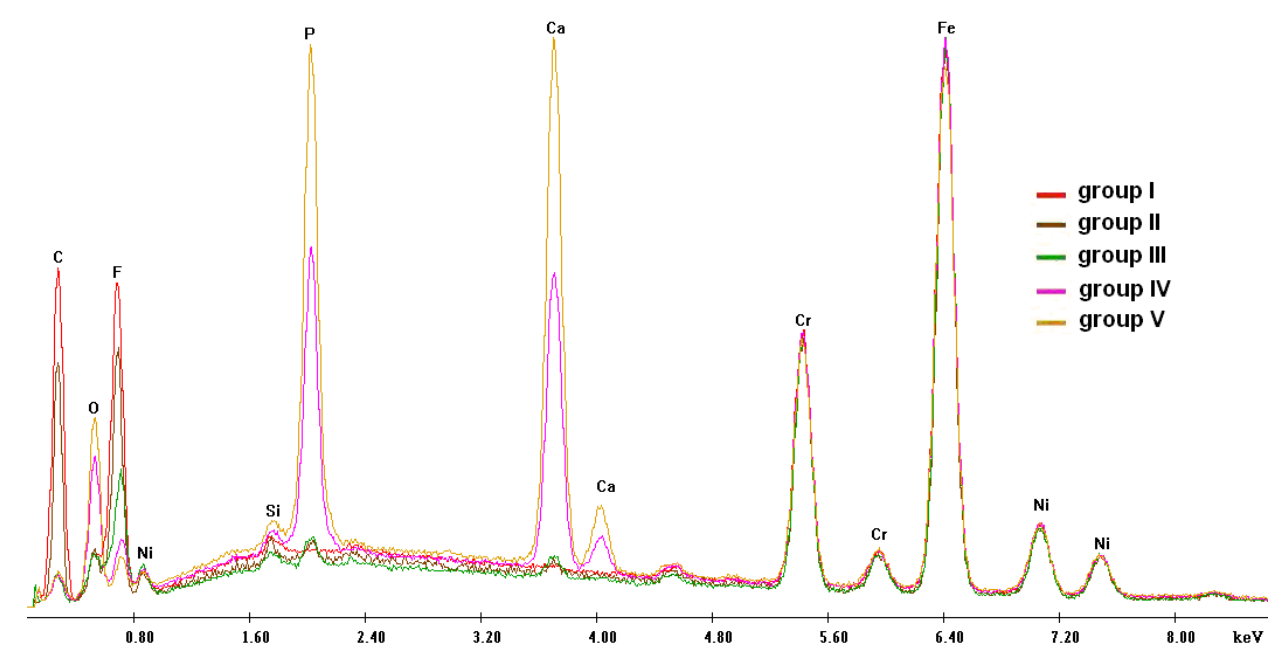

Figure 2. EDS profiles of the surfaces formed after various durations of the modification process.

Fig. 4 shows AFM images of relief (a), maps of the potential distribution (b) and the phase contrast (c) of the surface of the group I samples. The analysis of AFM images of the surface topography (see Fig 4) shows that the surface of the VDF-TeFE polymer coating is a homogeneous film which is formed by polymer globules of elongated ellipsoids with the dimensions of 1.02 and $0.71 \mathrm{~nm}$. The surface of the polymer coating formed on a metal substrate has a negative surface potential relative to the ground, which is associated with the electret properties of VDF-TeFE polymer [24-25]. Some areas of the surface have the potential shifted to positive relative to the mean by $0.25 \mathrm{~V}$ on average. The uneven distribution of surface potential on the dielectric polymer material was observed by the authors of [17]. Our studies show that areas of the positively shifted potential correspond to regions with distinct phase contrast and relief. Perhaps this is due to the fact that these areas are parts of the polymer that are in different crystal forms, corresponding to modern ideas about the structure of the VDF-TeFE copolymers [13].

Surface modification of polymer coating results in a significant change in its morphology, which is due to the impact on the surface of the plasma, which contains a large number of electrons, ions and radicals. The impact of plasma leads to the degradation of the polymer chains with the formation of low molecular weight degradation products. On the other hand the impact of the plasma leads to the formation of polymeric material on the surface of various functional groups of calcium phosphates, which are centers of crystallization of calcium phosphates, and the further growth of $\mathrm{CaP}$ coating $[26,27]$. 


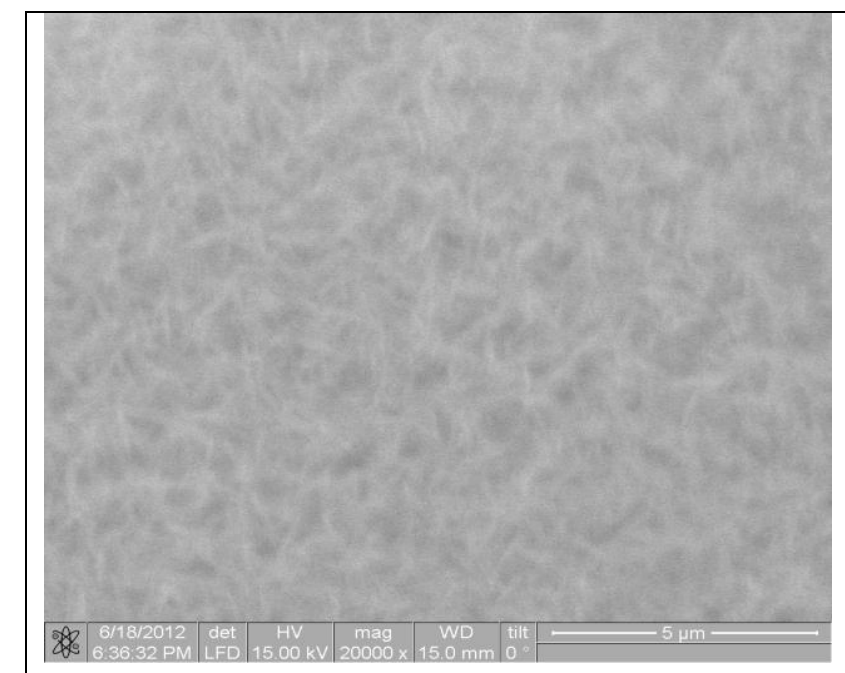

(a)

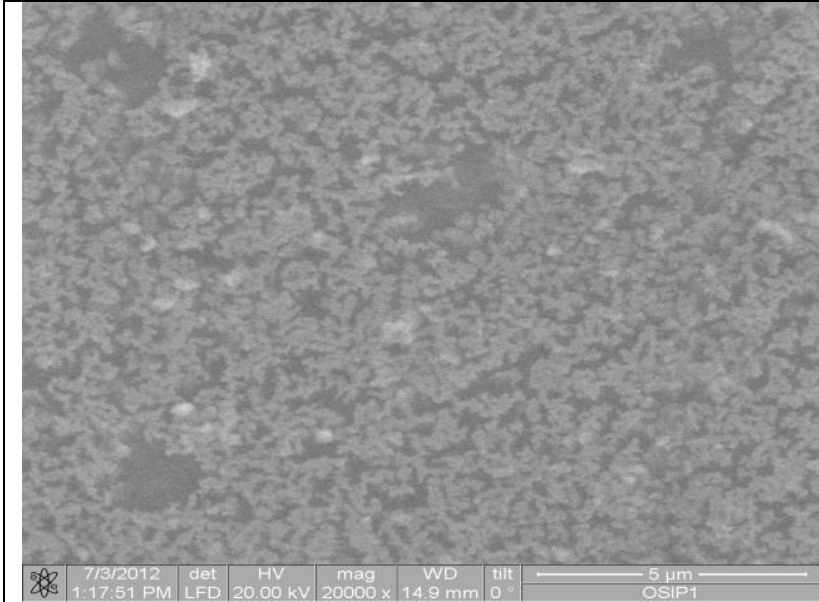

(c)

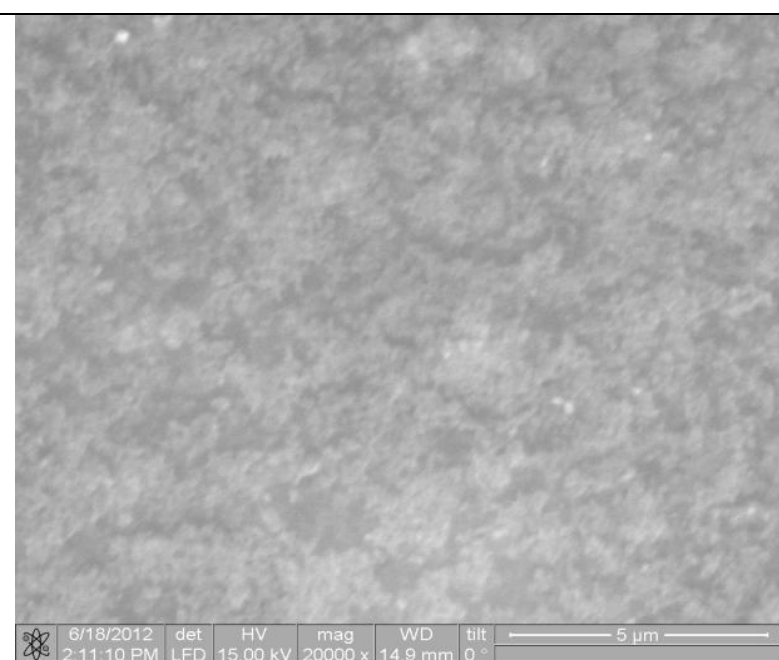

(b)

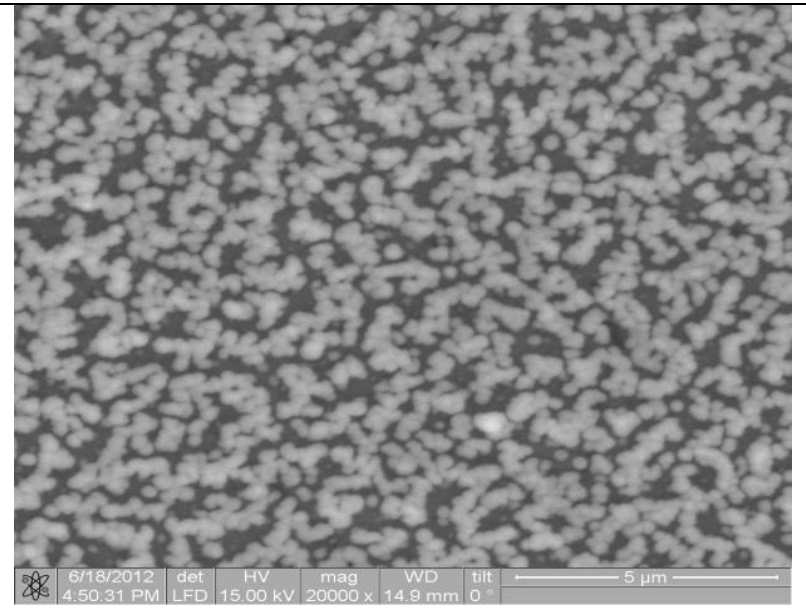

(d)

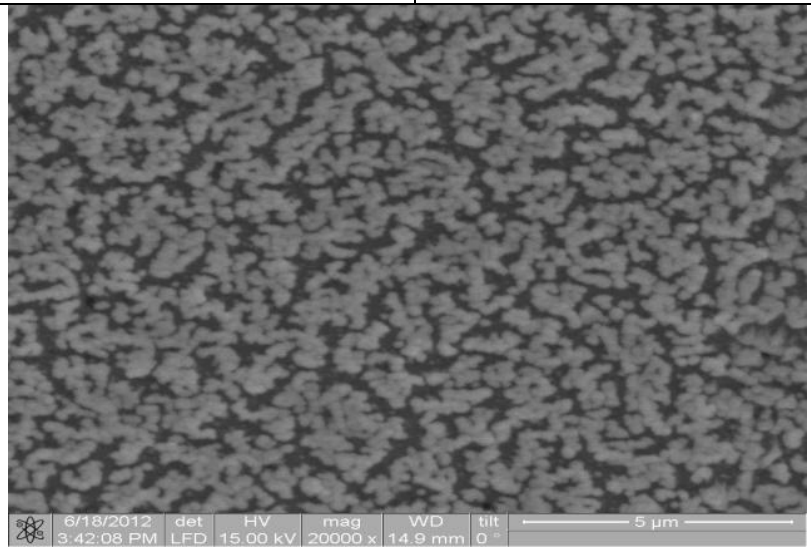

(e)

Figure 3. SEM image of the surface of samples of groups I (a), II(b), III(c), IV (d), V (e). 


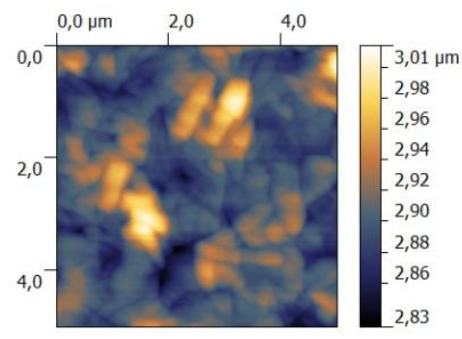

$a$

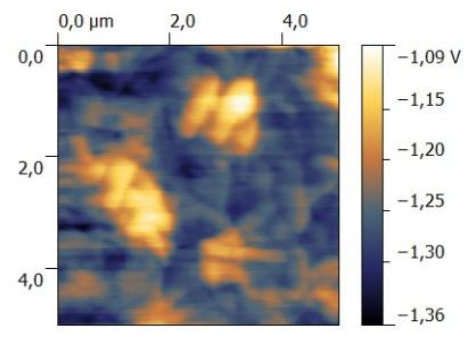

$b$

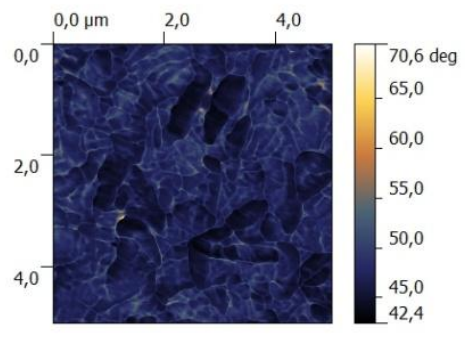

$c$

Figure 4. AFM images of the surface samples of the group I: a - relief, b - map of the distribution of the potential, $\mathrm{c}-$ the image of the phase contrast. The scanning area is 5 $\times 5 \mu \mathrm{m}$.

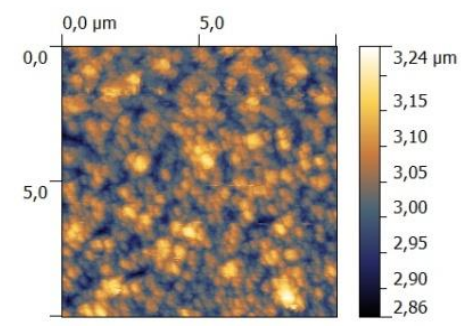

$a$

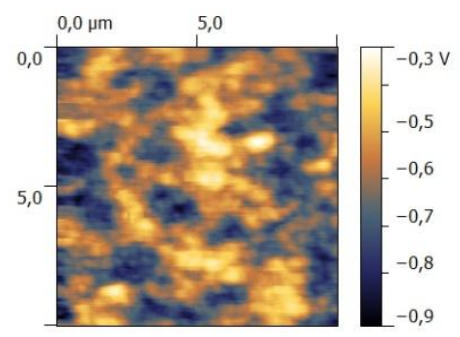

$b$

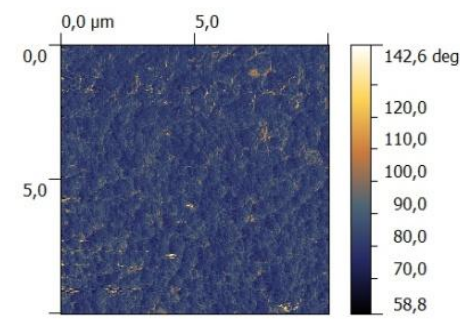

$c$

Figure 5. AFM images of the surface samples of the group II: a - relief, b - map of the distribution of the potential, $\mathrm{c}$ - the image of the phase contrast. The scanning area is $10 \times 10 \mu \mathrm{m}$.

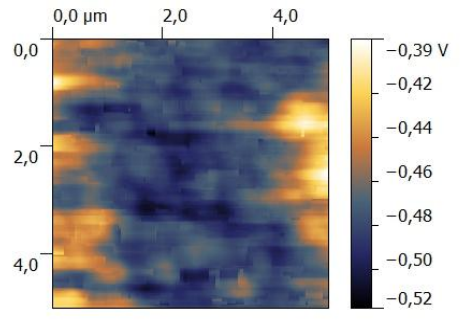

$a$

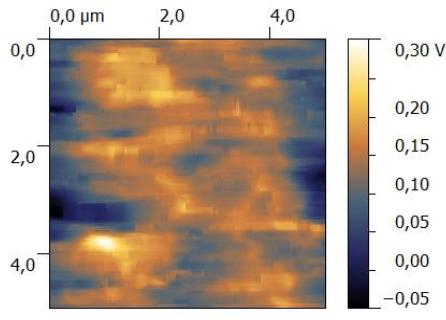

$b$

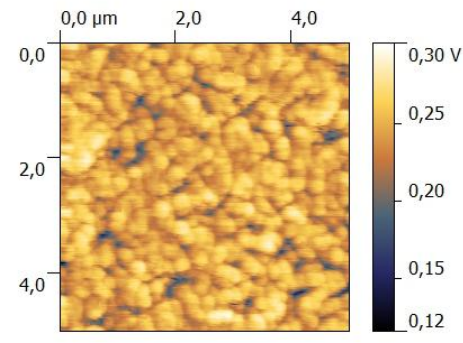

$c$

Figure 6. AFM images of the surface samples of the group $\mathrm{V}$ : $\mathrm{a}$ - relief, $\mathrm{b}$ - map of the distribution of the potential, $\mathrm{c}$ - the image of the phase contrast. The scanning area is $5 \times 5 \mu \mathrm{m}$. 
AFM images of surface topography of samples of group II (see Fig. 5) show that in the initial stages of formation of thin film of $\mathrm{CaP}$, it represents a conglomerate consisting of individual grains of size about $0.3 \mu \mathrm{m}$, completely covering the polymer layer, which is confirmed by the phase contrast image. The process of increasing the modification time is accompanied by grain growth of calcium phosphates, increase in size and merge to form islet structures (Fig. 3 b-d). Notably, increasing the modification time shifts the surface potential to positive values (Fig. 5, 6). Thus, by varying the time of the surface modification, there is a possibility of controlling the surface potential of the coating. This result demonstrates that the method of RFMS allows creating special surfaces suitable for the study of cell behavior on surfaces with different electric potential.

Higher magnifications AFM images (Fig. 7) ascertain that grains of the CaP film are positively charged and change the negative surface potential of the original polymer coating to the region of positive values (Table 2). Perhaps this is due to the fact that the CaP coating is a ptype semiconductor with a large band gap of about $4 \mathrm{eV}$ [28]. In [29] it was found that nanostructure of the surface of calcium phosphate has a high defect rate, and that the defects are the centers of the electron-hole capture, which can carry an electrical charge. Due to different mobility of electrons and holes these localized charges may be involved in the formation of electrical double layer and change the surface potential.

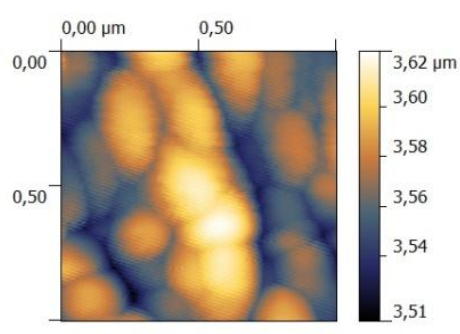

$a$

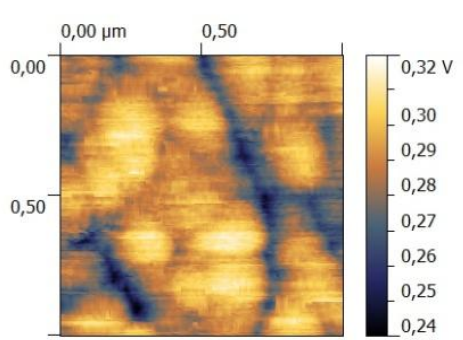

$b$

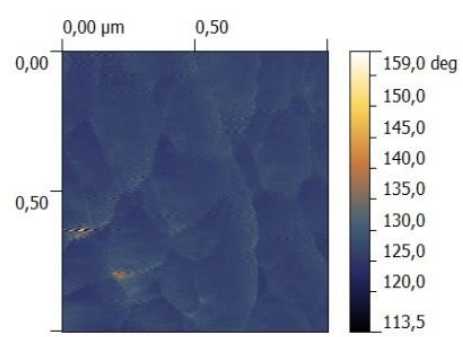

$c$

Figure 7. AFM images of the surface samples of the group V: a - relief, b - map of the distribution of the potential, $\mathrm{c}$ - the image of the phase contrast. The scanning area is $1 \times 1 \mu \mathrm{m}$.

Table 2. The dependence of substrate potential on the duration of modification of the polymer 
coating.

\begin{tabular}{|c|c|c|c|}
\hline $\begin{array}{c}\text { Group } \\
\text { number }\end{array}$ & $\begin{array}{c}\text { The mean value of the } \\
\text { surface potential } U_{\mathrm{m}}, \mathrm{V}\end{array}$ & $\begin{array}{l}\text { The minimum value of the } \\
\text { surface potential } U_{\min }, \mathrm{V}\end{array}$ & $\begin{array}{l}\text { The maximum value of } \\
\text { the } \\
U_{\max }, \mathrm{V} \\
\text { surface potential }\end{array}$ \\
\hline I & -1.2443 & -1.3626 & -1.0861 \\
\hline II & -0.6036 & -0.9021 & -0.3263 \\
\hline III & -0.4481 & -0.4884 & -0.3704 \\
\hline IV & 0.0817 & -0.1222 & -0.1873 \\
\hline V & 0.2290 & 0.0541 & 0.0315 \\
\hline
\end{tabular}

Table 3 presents the results of measurement of surface roughness of the samples of the groups I - V obtained using the software package Gwiddion 2.25. Basing on these data it can be concluded that the modification of the polymer coating by RF-magnetron sputtering leads to a change of the surface topography so that the surface roughness increases. This is due to two factors: 1) the influence of the plasma abnormal glow discharge on the coating polymer surface, which leads to erosion of the polymer surface; 2) the formation and growth of calcium phosphates spherulites which are centers of growth and crystallization of thin CaP films. It must be noted that the change of roughness parameters of the polymer coating is not linear with the duration of modification. For short-duration modification the roughness parameters increase and reach a maximum value at the 40 minutes duration. Due to longer RF-magnetron sputtering duration, a decrease of roughness parameters is observed, which, in our opinion, may be associated with consolidation and merging of calcium phosphates grains, which is evident in Fig.

3. The phenomenon of increasing of polymer surface roughness after modification can be used to stimulate the attachment and proliferation of cells such as bone marrow [30].

Table 3. Roughness parameters of the samples.

\begin{tabular}{|c|l|l|l|l|l|l|}
\hline $\begin{array}{c}\text { Group } \\
\text { number }\end{array}$ & $\begin{array}{l}\text { The mean } \\
\text { arithmetic } \\
\text { deviation of the } \\
\text { surface profile } \\
R a, \mathrm{~nm}\end{array}$ & $\begin{array}{l}\text { The height } \\
\text { of profile } \\
\text { irregularity } \\
\text { over ten } \\
\text { points } R z, \\
\text { nm }\end{array}$ & $\begin{array}{l}\text { The maximum } \\
\text { heigh Pt of profile } \\
\text { the } \\
\text { roughness, nm }\end{array}$ & $\begin{array}{l}\text { The average } \\
\text { maximum } \\
\text { depth of } \\
\text { roughness } \\
\text { valleys Rvm, } \\
\text { nm }\end{array}$ & $\begin{array}{l}\text { The average } \\
\text { maximum } \\
\text { height of } \\
\text { roughness } \\
\text { peaks Rpm, } \\
\text { nm }\end{array}$ \\
\hline I & 20.8 & 65.4 & 133.7 & 39.9 & 38.4 \\
\hline
\end{tabular}




\begin{tabular}{|c|c|c|c|c|c|}
\hline II & 27.1 & 112.3 & 142.5 & 47.9 & 51.6 \\
\hline III & 312 & 141.9 & 164.3 & 70.9 & 59.7 \\
\hline IV & 78.0 & 318.1 & 418.9 & 170.1 & 157.8 \\
\hline V & 52.6 & 205.0 & 341.3 & 123.8 & 102.1 \\
\hline
\end{tabular}

Fig. 8 shows images of water drops (top row) and glycerol (bottom row) placed on the surface of the samples of groups I, II and V.

The analysis of data of the wettability of the samples presented in Table 4 leads to conclusion that the simultaneous influence of the abnormal glow discharge plasma and formation of the thin $\mathrm{CaP}$ film lead to a significant change of the contact properties of the VDF-TeFE copolymer, the hydrophobic polymer surface becomes hydrophilic after modification. At the same time hydrophilicity of modified samples (groups II - V) changed nonlinearly with duration of modification. Samples of the group III (20-minute treatment) had maximum hydrophilicity and ones of the group V (60-minute treatment) had minimum hydrophilicity. One possible explanation for the hydrophilic properties of the coatings of groups II and III is the increased concentration of electronegative ions of calcium phosphates $\left(\mathrm{PO}_{4}{ }^{-}\right)_{3}$ (Table 1). The high concentration of electronegative ions of calcium phosphates has a tendency to attract positively charged ends of water molecules. Further increasing the duration of $\mathrm{CaP}$ coating leads to a decrease in the ratio $\mathrm{Ca} / \mathrm{P}$ (Table 1$)$ and the relative amounts of negatively charged ions $\left(\mathrm{PO}_{4}{ }^{-}\right)_{3}$ compared with the number of positively charged calcium ions, which leads to an increase in contact angle.
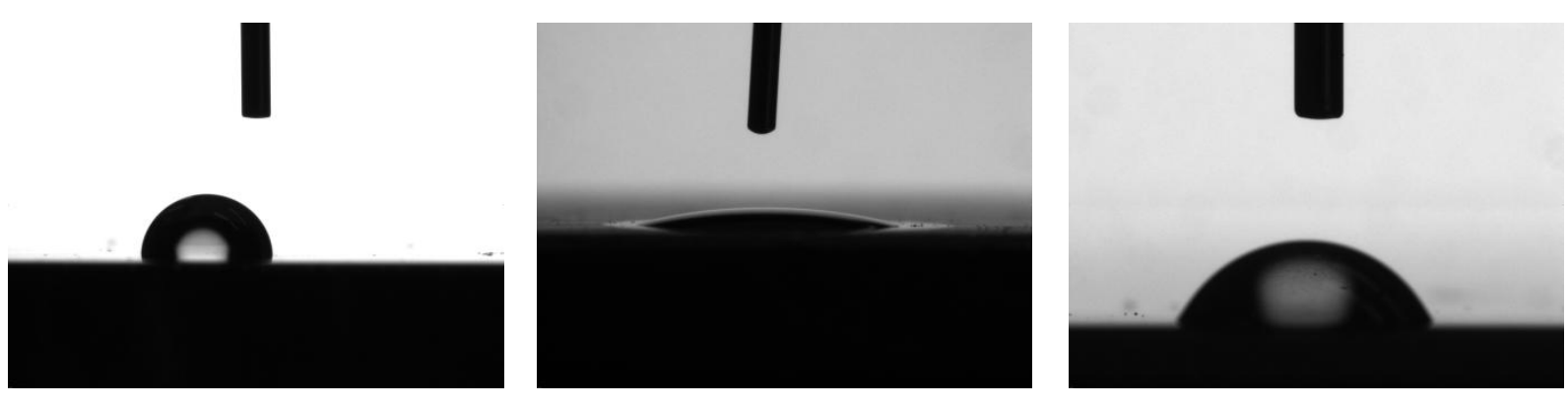


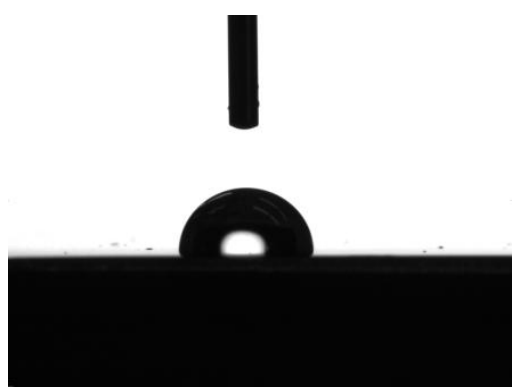

$a$

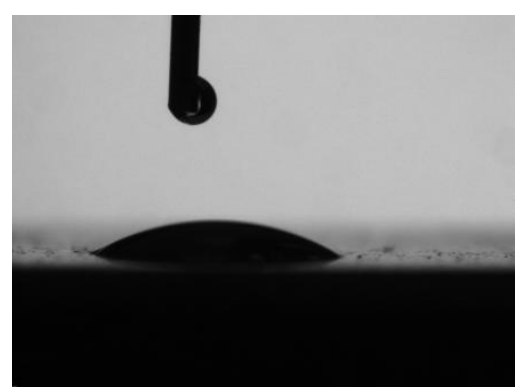

$b$

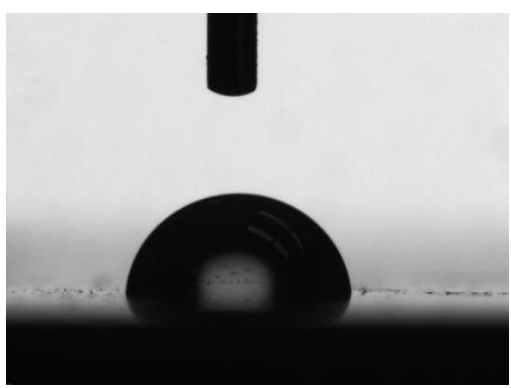

$c$

Figure 8. Images of liquid drops on the surface placed on samples a - group I, b - group II, c - group V, top row - water, bottom row - glycerol.

Table 4. The contact angles and surface energy of the samples.

\begin{tabular}{|c|r|r|r|r|r|}
\hline $\begin{array}{l}\text { Group } \\
\text { number }\end{array}$ & \multicolumn{1}{|l|}{$\begin{array}{l}\text { Contact angle } \\
\text { of water } \theta, \\
\text { degrees }\end{array}$} & $\begin{array}{l}\text { Contact } \\
\text { angle of } \\
\text { glycerol } \theta, \\
\text { degrees }\end{array}$ & $\begin{array}{l}\text { Free surface } \\
\text { energy } \gamma, \\
\mathrm{mJ} / \mathrm{m}^{2}\end{array}$ & $\begin{array}{l}\text { Dispersion } \\
\text { component } \\
\gamma^{\mathrm{d}}, \mathrm{mJ}^{2} \mathrm{~m}^{2}\end{array}$ & $\begin{array}{l}\text { Polar } \\
\text { component } \\
\gamma^{\mathrm{p}}, \mathrm{mJ}^{2} \mathrm{~m}^{2}\end{array}$ \\
\hline I & $100.7 \pm 1.2$ & $99.7 \pm 1.2$ & $12.1 \pm 1.4$ & $3.4 \pm 0.6$ & $8.7 \pm 0.9$ \\
\hline II & $19.2 \pm 1.2$ & $24.6 \pm 1.3$ & $70.2 \pm 1.7$ & $12.4 \pm 0.5$ & $57.8 \pm 1.2$ \\
\hline III & $10.2 \pm 1.1$ & $15.4 \pm 1.2$ & $72.7 \pm 1.3$ & $14.3 \pm 0.7$ & $58.4 \pm 0.6$ \\
\hline IV & $41.9 \pm 1.1$ & $42.5 \pm 1.4$ & $55.9 \pm 1.5$ & $11.9 \pm 0.6$ & $44.1 \pm 0.9$ \\
\hline V & $67.3 \pm 1.6$ & $85.0 \pm 1.3$ & $57 \pm 2$ & $0.45 \pm 0.19$ & $56 \pm 2$ \\
\hline
\end{tabular}

The calculation of the surface free energy (Table 4) was carried out by the OWRK method. The free surface energy values for groups II-V display progressively increasing values compared to control samples of the group I due to increase in the polar and dispersion components. The growth of the dispersion component for groups I-IV can be explained by the increase of surface roughness parameter [31]. The growth of the polar component can be explained by the increase of the number of polar groups, the electric charge and the free radicals appearance in the process of the modification of the polymer surface with the abnormal glow discharge plasma and ion sputtering target [32-33].

Overall, it appears that the most favorable for applications related to the regeneration of bone tissue are surface coatings of groups I and II that promote attachment, proliferation and 
differentiation of osteoblasts. This assumption is based on studies of wettability of the surface and the dependence of cell adhesion. Accordingly, Redey et al. [34], studying the behavior of osteoblasts, came to the conclusion that for the attachment of osteoblasts more hydrophilic surfaces are preferred. Spriano et al. [35] showed that the optimal distribution of fibroblasts was observed in the hydrophilic surface compared to hydrophobic.

Some scholars point to the dependence of the adsorption of proteins on the surface on its contact properties. The phenomenon of adsorption of proteins on the surface of the material is important, because the adsorbed proteins are a kind of trigger, starting the genetic program responsible for the processes of attachment, differentiation of osteoblasts and calcification, in which receptors are involved [36]. As a result, the hydrophobic surface, which are capable of greater absorption of proteins, tend to inhibit cell adhesion [37]. Thus, the coating of group I can be used in biomaterials to achieve low cell adhesion, such as needed in thrombotic resistant vascular stents, which, along with a high degree of surface cleanliness also require a negative surface potential. It is known that satisfying all these requirements ensures reliable operation of intravascular stents and reduces the likelihood of repeated surgical interventions [38].

The results of toxicity studies of samples of coatings obtained using cultures of motile cells are shown in Table 5.

Table 5. The index of the toxicity of modified samples of extracts derived from samples of the modified groups I - V

\begin{tabular}{|c|c|c|c|}
\hline $\begin{array}{c}\text { Group } \\
\text { number }\end{array}$ & Acceptable value \% & $\begin{array}{c}\text { Index of } \\
\text { toxicity } \%\end{array}$ & $\begin{array}{c}\text { Tolerability of } \\
\text { toxicity value }\end{array}$ \\
\hline I & $70-120$ & 88.4 & pass \\
\hline II & $70-120$ & 90.2 & pass \\
\hline III & $70-120$ & 95.2 & pass \\
\hline
\end{tabular}




\begin{tabular}{|c|c|c|c|}
\hline IV & $70-120$ & 98.6 & pass \\
\hline V & $70-120$ & 110.2 & pass \\
\hline
\end{tabular}

The modified samples showed no toxicity in-vitro and, thus, are potential candidates for use in medical applications. Thus, the results of the biocompatibility test of thin calcium-phosphate coatings produced by magnetron sputtering of hydroxyapatite coincide with previous results of other research group [39-40]. However, it must be stressed, that in accordance with international standard ISO 1099315 a number of other tests need to be employed to establish surface's biocompatibility. These tests depend on the application and the specifics and scope of the medical application in which coatings of groups I-V could be used. These tests are the subject of future studies.

\section{Conclusions}

In this paper a method for modification of the surface of the copolymer of Vinilidene Fluoride and Tetrafluoroethylene using RF-magnetron sputtering of hydroxyapatite is proposed.

The change in chemical composition, roughness parameters and potential contact surface properties was achieved after the formation of a thin $\mathrm{CaP}$ film while the abnormal glow discharge plasma was applied to the surface of the polymer.

Preliminary toxicity studies using in vitro cultures of motile cells demonstrated high biocompatibility of the coatings.

The proposed surface modification technique can be used to create coatings which, for example, facilitate the attachment and proliferation of osteogenic cells in order to create implants in orthopedics and traumatology.

Unmodified polymer surfaces have shown potential for their use as coatings with low adhesion of cells, such as required in thrombotic resistant vascular stents.

\section{Acknowledgment}


The work is performed with the support of Federal Target Program (state contract № 16.513.11.3075), RFBR (project № 11-08-98032-р_сибирь_a), state order (project № 7.1084.2011) and Carl Zeiss/OPTEC Grant N 86/11.

\section{References}

[1] U. Klinge, K. Junge, V. Schumpelick, B. Klosterhalfen, A.P. Öttinger, PVDF as a new polymer for the construction of surgical meshes, Biomater. 23 N 16 (2002) 3487-3493.

[2] Jian-Qiang Meng, Chun-Lin Chen, Li-Ping Huang, Qi-Yun Du, Yu-Feng Zhang, Surface modification of PVDF membrane via AGET ATRP directly from the membrane surface, Appl. Surf. Sci. 257 (2011) 6282-6290.

[3] B. Petersen, B.T. Uchida, H. Timmermans, F.S. Keller, J. Rosch, Intravascular US-guided direct intrahepatic portacaval shunt with a PTFE-covered stent-graft: feasibility study in swine and initial clinical results, J. Vasc. Interv. Radiol. 12 (2001) 475-486.

[4] A.M. Aronov, E.N. Bol'basov, V.V. Guzeev, M.V. Dvornichenko, S.I. Tverdokhlebov, I.A. Khlusov, Biological composites based on fluoropolymers with hydroxyapatite for intramedullary implants, Biomed. Eng. 44 N 3 (2010) 108-113.

[5] A.Vera, A. Schulte, Y. Hu, M. Diez, D. Bünger, M. Möller, M. C. Lensen, A hydrophobic perfluoropolyether elastomer as a patternable biomaterial for cell culture and tissue engineering, Biomater. 31 (2010) 8583-8595.

[6] S.I. Tverdokhlebov, E.N. Bolbasov, E.V. Shesterikov, Scaffold materials based on fluorocarbon composites modified with RF magnetron sputtering, in: Yunfeng Lin (Ed.), Osteogenesis, InTech, Rijeka, 2012, pp. 83 - 116.

[7] I.A. Khlusov, A.V. Karlov, Yu.P. Sharkeev, V.F. Pichugin, Yu.R. Kolobov, G.A. Shashkina, M.B. Ivanov, E.V. Legostaeva and G.T. Sukhikh, Osteogenic potential of mesenchymal stem cells from bone marrow in situ: role of physicochemical properties of artificial surfaces, Bull. Exp. Biol. Med. 140 N 1 (2005) 144-152.

[8] M. Levin, Large-scale biophysics: ion flows and regeneration, Trends Cell Biol. 17 (2007) 261-270.

[9] C.D. McCaig, A.M. Rajnicek, B. Song, M. Zhao, Controlling cell behavior electrically: 
Current views and future potential, Physiol. Rev. 85 (2005) 943-978.

[10] D. Klee, Z. Ademovic, A. Bosserhoff, H. Hoecker, G. Maziolis, H. Erli, Surface modification of poly(vinylidenefluoride) to improve the osteoblast adhesion, Biomater. 24 (2003) 3663-3670.

[11] Y.W. Park, N.A. Inagaki, A new approach for selective surface modification of fluoropolymers by remote plasmas, J. Appl. Polym. Sci. 93 (2004) 1012-1020.

[12] S.D. Pacetti, S.F.A. Hossainy, N. Ding, W.E. Roorda, Coatings for implantable medical devices and methods for fabrication thereof, Application number: 10/251,111, Publication number: US 2004/0063805 A1, Filing date: 19 Sep 2002.

[13] Yu.A. Panshin, S.G. Malkevich, Ts.S. Dunaevskaya, Ftoroplats, L. Chimia, Moscow, 1978. [14] S.M. Rossnagel, in: W.D. Sproul, K.O. Legg (Eds.), Sputter deposition. Opportunities for innovation, Advanced Surface Engineering, Technomic Publishing Co., Switzerland, 1995.

[15] A.M. Aronov, V.F. Pichugin, E.V. Eshenko, M.A. Ryabtseva, R.A .Surmenev, S.I. Tverdokhlebov, E.V. Shesterikov, Thin calcium-phosphate coatings produced by RF magnetron sputtering and prospects for their use in biomedical engineering, Biomed. Eng. 42 (2008) 123127.

[16] H. Yamada, T. Fukuma, K. Umeda, K. Kobayashi, K. Matsushige, Local structures and electrical properties of organic molecular films investigated by non-contact atomic force microscopy, Appl. Surf. Sci. 188 (2002) 391-398.

[17] H.T. Baytekin, A.Z. Patashinski, M. Branicki, B. Baytekin, S. Soh, B.A. Grzybowski, The mosaic of surface charge in contact electrification, Sci., 333 (2011) 308-312.

[18] K. Owens, R.C. Wendt, Estimation of surface free energy of polymers, J. Appl. Polym. Sci. 13 (1969) 1741D-1747D.

[19] D. Janssen, R. Palma, S. Verlaak, P. Heremans, W. Dehaen, Static solvent contact angle measurements, surface free energy and wettability determination of various self-assembled monolayers on silicon dioxide, Thin Solid Films, 515 (2006) 1433-1438.

[20] A.P. Eskov, R.I. Kayumov, A.E. Sokolov, Dynamic, label free test for in vitro cytotoxicity, Toxicol. Lett. 211S (2012) S148. 
[21] W. Tong, J. Chen, X. Li, J. Feng, Y. Cao, Z. Yang, X. Zhang, Preferred orientation of plasma sprayed hydroxyapatite coatings, J. Mater. Sci., 31 (1996) 3739-3742.

[22] V. Nelea, C. Morosanu, M. Iliescu, I. Mihailescu, Hydroxyapatite thin films grown by pulsed laser deposition and radio-frequency magnetron sputtering: comparative study, Appl. Surf. Sci. 228 (2004) 346-356.

[23] S.H. Han, H.J. Kim, I.K. Kang, J.J. Lee, Influence of argon pressure on the composition of Co-early transition metal films fabricated by r.f. magnetron sputtering in the composite target mode, J. Mat. Sci., 28 (1993) 3267-3271.

[24] V.V. Kochervinskii, V.F. Romadin, V.A. Glukhov, V.G. Sokolov, M.A. Saidakhmetov, Structural aspects of piezo-electricity in the copolymer of vinylidene fluoride and tetrafluoroethylene, Polym. Sci. U.S.S.R., 31, (1989) 1511-1519.

[25] N. Weber, Y.S. Lee, S. Shanmugasundaram, M. Jaffe, T.L. Arinzeh, Characterization and in vitro cytocompatibility of piezoelectric electrospun scaffolds, Acta Biomater. 6 (2010) 35503556.

[26] N. Inagaki, Plasma surface modification and plasma polymerization, Technomic Pub., Lancaster, 1996.

[27] S. Xu, J. Long1, L. Sim, C.H. Diong, K. Ostrikov, RF plasma sputtering deposition of hydroxyapatite bioceramics: synthesis, performance, and biocompatibility, Plasma Process. Polym. 2 (2005) 373-390.

[28] G. Rosenman, D. Aronov, Wettability engineering and bioactivation of hydroxyapatite nanoceramics, Intern. Tech. Proc. Nanotech. Conf., 2 (2006), 91-94.

[29] D. Aronov, G. Rosenman, Traps states spectroscopy studies and wettability modification of hydroxyapatite nano-bio-ceramics, J. Appl. Phys. 101 (2007) 034701-034701-5.

[30] J.E.G. Hulshoff1, K. van Dijk1, J.P.C.M. van Der Waerden1, J.G.C. Wolke1, L.A. Ginsel, J.A. Jansen, Biological evaluation of the effect of magnetron sputtered $\mathrm{Ca} / \mathrm{P}$ coatings on osteoblast-like cells in vitro, J. Biomed. Mater. Res. 29 (1995) 967-975.

[31] A. Fridman, Plasma chemistry, Cambridge University Press, New York, 2008.

[32] R.Z. LeGeros, Calcium phosphate-based osteoinductive materials, Chem. Rev. 108 (2008) 
[33] D. Aronov, G. Rosenman, Surface energy modification by electron beam, Surf. Sci. 601 (2007) 5042-5049.

[34] S.A. Redey, M. Nardin, D. Bernache-Assolant, C. Rey, P. Delannoy, L. Sedel, P.J. Marie, Behavior of human osteoblastic cells on stoichiometric hydroxyapatite and type A carbonate apatite: role of surface energy, J. Biomed. Mater. Res. 50 (2000) 353-364.

[35] S. Spriano, M. Bosetti, M. Bronzoni, E. Verne, G. Maina, V. Bergo, M. Cannas, Surface properties and cell response of low metal ion release Ti-6Al-7Nb alloy after multi-step chemical and thermal treatments, Biomater. 26 (2005) 1219-1229.

[36] E. Vogler, Interfacial chemistry in biomaterials science, in: Berg J, (Ed.) Wettability, Surfactant science series 49, Marcel Dekker, New York, 1993, pp. 184-250.

[37] M.A. Lopes, F.J. Monteiro, J.D. Santos, A.P. Serro, B. Saramago, Hydrophobicity, surface tensions, and zeta potential measurements of glass-reinforced hydroxyapatite composites, J. Biomed. Mater. Res. 45 (1999) 370-375.

[38] G. Mania, M.D. Feldman, D. Patel, C.M. Agrawal, Coronary stents: A materials perspective, Biomat. 28 (2007) 1689-1710.

[39] J.A. Jansen, J.G.C. Wolke, S. Swann, J.P.C.M. Van Der Waerden, K. De Groof, Application of magnetron sputtering for producing ceramic coatings on implant materials, Clin. Oral Implant. Res. 4 (1993) 28-34.

[40] J.Z. Shi, C.Z. Chen, H.J. Yu, S.J. Zhang, Application of magnetron sputtering for producing bioactive ceramic coatings on implant materials, Bull. Mater. Sci. 6 (2008) 877-884. 